\title{
Familial and Peer Influences on Sport Participation among Adolescents in Rural South African Secondary Schools
}

\author{
Ntwanano A. Kubayi \\ Julius Jooste \\ Abel L. Toriola \\ Yvonne Paul \\ Department of Sport, Rehabilitation and Dental Sciences, Tshwane University of Technology, \\ Private Bag X680, Pretoria, 0001, South Africa \\ Email:Kubayina@tut.ac.za
}

\section{Doi:10.5901/mjss.2014.v5n20p1305}

\section{Abstract}

This study was designed to investigate the influences of family and peers on sport participation amongst adolescents in secondary schools at Hlanganani rural area of Limpopo Province, South Africa. A total of 172 learners (108 females and 64 males) attending three public secondary schools in Hlanganani rural area volunteered to participate in the study. Results indicated that adolescents preferred peers to family for support in sport participation. In terms of gender, no significant differences $(p>0.05)$ were noted between mean values for school boys and girls with regard to family influence. Boys reported more tangible support, whereas girls indicated a preference for emotional support. Sport participation among learners is likely to increase when they receive informational, tangible, emotional and appraisal support from their parents and peers.

Keywords: Family, peers, influence, sport, participation.

\section{Introduction}

Regular sport participation plays an important role in promoting students' well-being. Sport participation develops students physically, socially and psychologically (Kubayi, Toriola \& Monyeki, 2013) and helps them to cope with stress as well as improve academic performance, and school attendance. Previous researchers (Wann, 1997; Sallis \& Owen, 1999; Sallis, Prochaska \& Taylor, 2000) have demonstrated that factors such as media, family (parents and siblings), peers, physical education teachers and community members influence children's participation in sport and physical activity. However, research has also shown that adolescents are mainly influenced by their families and peers. According to Middleton and Loughead (1993), adolescents are less influenced by peers when they have close and involving relationships with their parents. The authors further contended that the ability of peers to influence the behaviours and attitudes of adolescents is magnified when adolescents hold negative perceptions about their parental relationship. This study is grounded on the principles of the socio-emotional selection theory which implies that people often turn to their friends rather than family (Potts, 1997) for sport participation. A qualitative study conducted by Weiss, Smith and Theeboom (1996) indicated that children turn to their friends for the following positive dimensions: companionship (spending time or hanging out together); pleasant play association (enjoying being around one's friends); enhancement of self-esteem (friends saying things or taking actions that boost one's self-esteem); help and guidance (friends providing assistance relative to learning sport skills). The other positive dimensions identified by Weiss et al. (1996) included intimacy (mutual feelings of close personal bonds); loyalty (a sense of commitment to one another); things in common (sharing interests); emotional support (expressions and feelings of concern for one another); absence of conflicts (some friends do not argue, fight or disagree) and conflict resolution (other friends are able to resolve conflicts). Peers are not only influential in sport but also in other aspects of life. This view was reiterated by Alika (2012) who asserted that the quality of the relationship between adolescents and their peers, as well as the type of peers they associate with, play important roles in aiding or impeding their career choices. Families provide adolescents with the resources that peers cannot afford. For instance, families provide material resources (sport kit, equipment) and emotional support such as love, attention, and belonging (Robinson \& McCormick, 2011). According to Kay (2004), a family is considered a primary 
agent of socialization through which children develop their own identity and learn the norms and values of the society in which they live. Therefore, family, in particular parents, have also been shown to influence their children's experiences in sport (Fredricks \& Eccles, 2004). In contrast, Kirby, Levin and Inchley (2011) reported that adolescents are increasingly influenced by their peers. With these uncertainties in view, this study was primarily designed to examine familial and peer influences on sport participation among rural secondary school learners.

\section{Methodology}

\subsection{Sample}

A total of 172 learners, aged $18.37 \pm 1.90$ years and attending three public secondary schools in Hlanganani rural area, Limpopo Province of South Africa, volunteered to participate in the study.

\subsection{Instrument}

A questionnaire developed by Lau, Fox and Cheung (2005) was used to collect data. The instrument had three sections. Section A comprised questions which sought information on the participants' demographic profile (age and gender). Section $B$ and $C$ elicited information on family sport orientation and peer influences on sport participation respectively. The items were scored on a 5-point Likert scale ranging from 1 (strongly disagree), 2 (disagree), 3 (neutral), 4 (agree) and 5 (strongly agree). Overall Cronbach alpha coefficients of .66 and .77 were obtained for peer influences and family sport orientation, respectively. The lowest value of a .66 was noted in family sport orientation, being lower than the value recommended by Nunnally (1978) (a .7); however this value is higher than the lowest permissible threshold of a .6 (Diamantopoulos \& Winklhofer, 2001).

\subsection{Ethical consideration}

Prior to data collection, permission to conduct the study was granted by the Department of Education at Vhembe district, Thohoyandou and Hlanganani circuit office at Hlanganani rural area, Limpopo Province (Reference number: 14/7/R). Signed informed consent was obtained from all learners who participated in the study. All participants were informed that participation was voluntary and were assured of anonymity and confidentiality of their responses. The learners were also informed that they could withdraw from the study at any time, without giving any explanation.

\subsection{Data collection procedure}

Supervised data collection was undertaken by trained fieldworkers who were school teachers. To avoid disruption of school lessons, data was collected after school hours with the permission of school principals. Participants were guided to fill in the questionnaires independently which took the learners approximately 15-20 minutes to complete.

\subsection{Data analysis}

The data was captured and analysed using the SPSS, version 21. Means, standard deviations and percentages were used to analyse the data. An Independent t-test was applied to examine whether any gender differences existed in the dependent measures. A probability level of 0.05 or less was used to indicate significance.

\section{Results}

The mean and standard deviation of the family sport orientation and peer influences on sport participation are provided in Table 1. In terms of the mean ranking of the variables relating to the influence of friends, both boys and girls indicated that their friends encourage them to participate in sport, they think sport is important and play sport together as the most important reasons for sport participation. T-test was used to examine the differences between boys and girls and yielded significant differences regarding the following variables: "My friends want me to participate in sport" $(\mathrm{t}=-3.697, \mathrm{p}=.000)$ and "I gain higher status with my friends", (t= -3.539, $p=.001)$. 
Table 1: Descriptive statistics of family sport orientation and peer influences on sport participation between boys and girls

\begin{tabular}{|c|c|c|c|c|}
\hline \multirow{2}{*}{ Variable } & \multirow{2}{*}{$\frac{\text { Boys }}{\text { M SD }}$} & \multicolumn{2}{|c|}{ Girls } & \multirow[b]{2}{*}{ p-value } \\
\hline & & M SD & t-value & \\
\hline \multicolumn{5}{|l|}{ Friends and sport subscale: } \\
\hline My friends want me to participate in sport. & 3.161 .44 & 2.321 .42 & -3.697 & $.000 *$ \\
\hline My friends play sport with me. & 3.421 .48 & 3.291 .30 & -.623 & .534 \\
\hline I gain higher status within my friends. & 3.301 .39 & 2.511 .42 & -3.539 & $.001^{\star}$ \\
\hline My friends come to watch me playing sport. & 3.311 .38 & 3.191 .31 & -.603 & .547 \\
\hline My friends encourage me. & 3.781 .30 & 3.901 .14 & .618 & .538 \\
\hline My friends think sport is important & 3.681 .38 & 3.411 .47 & -1.165 & .246 \\
\hline Family and sport subscale: & 3.11 .22 & 2.491 .50 & -.1389 & .167 \\
\hline My parents are active sport participants. & 2.481 .52 & 2.401 .32 & -.377 & .707 \\
\hline My parents take me to sports grounds. & 2.441 .46 & 2.561 .38 & -.574 & .567 \\
\hline My parents like to play sport with me. & 3.161 .52 & 3.521 .34 & 1.580 & .117 \\
\hline My parents like to watch me playing sport. & 3.761 .42 & 3.911 .23 & .705 & .482 \\
\hline I think my family will support me if I decide to participate in sporting events. & 2.831 .38 & 3.051 .31 & 1.035 & .302 \\
\hline My parents regard us as a sporty family. & 3.161 .49 & 3.411 .31 & 1.113 & .268 \\
\hline My family feel important to watch, play or attend sporting events. & 2.691 .37 & 2.791 .28 & .480 & 632 \\
\hline I feel my family is 'sporty.' & 2.551 .50 & 2.731 .39 & .817 & .415 \\
\hline Sport is one of the main topics among fan & & & & \\
\hline
\end{tabular}

Overall, the boys reported more peer support than the girls. Furthermore, the standard deviations for the friends subscale do not demonstrate great dispersion which indicates homogeneity. In terms of the mean ranking of the family influence, boys indicated that their families will support them if they decide to participate in sport. The most important reasons for this are that parents and families feel that it is important to watch or attend their sporting events and are active sport participants. Girls feel the same way and parents therefore regard their family as being sporty. No significant $(p>0.05)$ differences were noted between mean values for males and females with regard to family influence.

\section{Discussion}

This study examined family and peer influences in sport participation among adolescents in rural secondary schools in Hlanganani, Limpopo Province of South Africa. The current study found that adolescents (boys and girls) received more support from their peers than their families. Consistent with the findings of a previous study (Brustad, Babkes \& Smith, 2001) the current study demonstrates that peers become influential during adolescence. However, a possible explanation for this finding could be due to the fact that parents in rural areas do not bond much with their children since they spend most of their time at work, in cities and farms. Therefore, adolescents may seek affiliation needs such as companionship and intimacy from their peers. This view is further confirmed by Alika (2010) who contended that when there is an expanded distance between parents and children, adolescents are more likely to be shaped by the impact of their peers.

Additionally, the present study also found that girls reported more family support than boys. This finding contradicts those of a previous study (Trost et al., 2003) which found that parents reported providing significantly higher levels of social support to boys compared to girls. This finding is surprising given the typical lifestyle associated with rural living. We had anticipated that due to the perception in cultures of Black people that sport participation is not ideal for girls due to their preoccupation with household chores. Therefore, there is a tendency for families to view sport participation positively for boys in contrast to girls. This finding could be explained in the light of educated parents in rural areas who are aware of the benefits of sport. Research has shown that adolescents whose parents have attained higher education levels are more likely to participate in organised sport, structured exercise and games play in their leisure time than those with parents with lower education levels (Ommundsen, Klasson-Heggebo \& Anderssen, 2006).

Another important finding which emerged from this study is that the majority of girls indicated that their parents like to watch them when they play sports. This finding is consistent with a previous study conducted by Wilson et al. (1999) which reported that girls have been characterized as more expressive and comfortable with intimacy and more likely to seek out and prefer emotional support. Research has shown that emotional support increases self-confidence, a feeling of life satisfaction and the ability to cope with stress, as well as decreasing the incidence of depression in adolescents (Milevsky, Schlechter, Netter \& Keehn, 2007; Oliva, Jimenez \& Parra, 2009). On the other hand, boys reported more tangible support (e.g., "My parents take me to sports grounds") than girls. This finding highlights the need to provide boys with tangible assistance such as buying sport equipment and transport or rides to and from practice or games. 


\section{Conclusion}

In this study adolescents seem to prefer peers to family in terms of providing support for sport participation. The findings of this study have practical implications for promoting sport participation in rural areas. Since parents hardly spend time with their children in rural areas, various stakeholders such as school teachers, sport coaches and community members should play a prominent role by acting as loco parentis to learners and should be involved in motivating and encouraging adolescents to participate in school sports. Furthermore, schools should ensure that all learners are given the necessary support and ample opportunity to participate in school sports irrespective of their race, ability, gender, age, religion, disability, language and culture.

\section{References}

Alika, H.I. (2010). Parental and peer group influence as correlates of career choice in humanities among secondary school students Edo State Nigeria. Journal of Research in Education and Society, 1 (1), 178-185.

Alika, H.I. (2012). Career choice in engineering: The influence of peers and parents implication for counselling. College Student Journal, 46 (3): 537-542.

Brustad, R. J., Babkes, M. L. \& Smith, A. L. (2001). Youth in sport: Psychological considerations. In R. N. Singer, H. A. Hausenblas, C. M. Janelle (Eds.), Handbook of sport psychology (pp. 604-635). New York: Wiley.

Diamantopoulos, A. \& Winklhofer, H.M. (2001). Index construction with formative Indicators: An alternative to scale development. Journal of Marketing Research, 38, 269-277.

Fredricks, J. A. \& Eccles, J. S. (2004). Parental influences on youth involvement in sports. In Weiss, M. R. (Ed.), Developmental Sport and Exercise Psychology: A Lifespan Perspective (pp. 145-164). Morgantown, WV: Fitness Information Technology.

Kay T. (2004). The family factor in Sport: A review of factors affecting sports participation. In Sport England (ed.), Driving up participation: the challenge for sport. London: Sport England.

Kirby, J., Levin, K. A. \& Inchley, J. (2011). Parental and peer influences on physical activity among Scottish Adolescents: A Longitudinal Study. Journal of Physical Activity and Health, 8, 785-793

Kubayi, N.A., Toriola, A.L. \& Monyeki, M.A. (2013). Barriers to school sport participation: A survey among secondary school students in Pretoria, South Africa. African Journal for Physical, Health Education, Recreation and Dance, 19(2), 336-344.

Lau, P.W.C., Fox, K.R. \& Cheung, M.W.L (2005). Psychosocial and socio-environmental correlates of sport identity and sport participation in secondary school-age children. European Journal of Sport Science, 4 (3), 1-21

Middleton, E. \& Loughead, T. (1993). Parental influence on career development. An integrative frame work for adolescent career counselling. Journal of Career Development, 18, 161-173

Milevsky, A., Schlechter, M., Netter, S. \& Keehn, D. (2007). Maternal and paternal parenting styles in adolescents: associations with selfesteem, depression and life-satisfaction. Journal of Child and Family Studies, 16, 39-47.

Nunally, J. C. (1978). Psychometric Theory. New York: McGraw Hill

Oliva, A.; Jimenez, J.M. \& Parra, A. (2009). Protective effect of supportive family relationships and the influence of stressful life events on adolescent adjustment. Anxiety, Stress and Coping, 22, 137-52.

Ommundsen, Y., Klasson-Heggebo, L. \& Anderssen, S. (2006). Psycho-social and environmental correlates of location-specific physical activity among 9- and 15- year-old Norwegian boys and girls: the European Youth Heart Study. International Journal of Behavioural of Nutrition and Physical Activity, 3(32).

Potts, M.K. (1997). Social support and depression among older adults living alone: The importance of friends within and outside of the retirement community. Social work, 42, 348-362.

Robinson, J. \& Mccormick, D.J. (2011). Concepts in health and wellness. New York: Delmar Cengage Learning.

Sallis, J.F. \& Owen, N. (1999). Physical activity and behavioural medicine. London: Sage Publications.

Sallis, J.F., Prochaska, J.J. \& Taylor, W.C. (2000). A review of correlates of physical activity of children and adolescents. Medicine and Science in Sports and Exercise, 32, 963-75.

Trost, S., Sallis, J., Pate, R., Freedson, P.S., Taylor, W.C. \& Dowda, M. (2003). Evaluating a model of parental Influence on youth physical activity. American Journal of Preventive Medicine, 25, 277-82.

Wann, D. L. (1997). Sport Psychology. New Jersey: Prentice Hall.

Weiss, M.R.; Smith, A.L. \& Theeboom, M. (1996). "That's what friends are for": Children's and teenagers' perceptions of peer relationships in the sport domain. Journal of Sport and Exercise Psychology, 18, 347-379.

Wilson, D.K., Kliewer, W., Bayer, L., Jones, D., Welleford, A., Heiney, M. \& Sica, D.A. (1999). The influence of gender and emotional versus instrumental support on cardiovascular reactivity in African-American adolescents. Annals of Behavioural Medicine, 21, $235-43$. 